\title{
USING THE THEORY OF REASONED ACTION TO PREDICT SMOKING INTENTION AMONG NON-SMOKING SECONDARY SCHOOL GOING ADOLESCENTS IN PENINSULAR MALAYSIA
}

\author{
Kuang Hock Lim¹, Hui Li Lim², Sumarni Mohd Ghazali ${ }^{1}$, Chee Cheong Kee ${ }^{3}$, Mohd Zainuldin Taib ${ }^{1}$, Yoon \\ Ling Cheong ${ }^{1}$, Yong Kang Cheah ${ }^{4}$, Syazwan Aizat Ismail ${ }^{5}$ and Pei Pei Heng ${ }^{1}$ and Jia Hui Lim ${ }^{6}$ \\ ${ }^{1}$ Institute for Medical Research, Ministry of Health Malaysia, Jalan Pahang, 50588 Kuala Lumpur \\ ${ }^{2}$ Hospital Sultan Ismail, Ministry of Health Malaysia, Taman Mount Austin, 81100 Johor \\ ${ }^{3}$ Sector for Biostatistic and Repository Data, National Institutes of Health, Ministry of Health Malaysia, Setia Alam, \\ 40170 Shah Alam, Selangor \\ ${ }^{4}$ School of Business Finance and Banking, College of Business, University Utara Malaysia, 06010 Sintok, Kedah \\ ${ }^{5}$ Institut Latihan Kementerian Kesihatan Sungai Buloh, Ministry of Health Malaysia, Jalan Hospital,47000, Sungai Buloh, \\ Selangor. \\ ${ }^{6}$ Monash University Malaysia, Bandar Sunway, 45700 Subang Jaya, Selangor
}

Corresponding author: Lim Kuang Hock

Email: limkh@moh.gov.my

\begin{abstract}
The study aims to determine the relationship of attitude and social-norm with intention to smoke in the future among non-smoking youth. Data were derived from a study on smoking among form four students in selected secondary school in Peninsular Malaysia, which utilised a pre-validated questionnaire to obtain data from the selected respondents. Descriptive statistics and structural equation modelling (SEM) were used in data analysis. The study revealed independent variables accounted for $22.6 \%$ of the variance in intention to initiate smoking and the model had good fit. A significant relationship was observed between subjective norm and intention to initiate smoking $(R=0.46)$. The study revealed that attitude and social norm substantially explained intention to smoke among non-smoking adolescents. Future measures should concentrate on correcting the subjective norms to reduce intention to initiate smoking among non-smoking youth.
\end{abstract}

Keywords: Intention to smoke, attitude, subjective norms, non-smoking adolescents

\section{INTRODUCTION}

Tobacco use is the leading preventable cause of death in the Malaysia and is responsible for an estimated 20,000 deaths annually ${ }^{1}$, and the mortality rate is likely to increase to 30,000 by 2020 if there are no changes in the current trend of smoking ${ }^{1}$. Multitude studies have revealed that smoking is learned and started during adolescence ${ }^{2,3,4}$. Children and adolescents are the most vulnerable of experimental smokers (smoking one or two puffs of a cigarette) and are more likely to progress to current smokers ${ }^{5}$. Once adolescents begin to experiment with smoking, they are likely to become regular smokers and the earlier individuals start smoking, the higher their risk of addiction in later life ${ }^{6}$. Therefore, reducing smoking initiation is among the longterm measures to reduce smoking prevalence among adults, and diseases related to smoking in the future.

Various studies (cross-sectional and longitudinal studies), have shown that intention is a reliable predictor of future behaviour, including of smoking initiation ${ }^{7,8}$. The Theory of Reasoned Action (TRA), developed by Fishbein and Ajzen $1975^{9}$, is a theory which focuses on behavioural intent, in which intention is influenced by cognitive components, consisting of attitudes and subjective norms. According to this theory, people's attitudes toward a certain behaviour and norms representing their perception of other people's views of such behaviour will determine their behavioural intentions, which may further lead to performance of the behaviour. The validity of this concept has led researchers to conduct further studies to identify the factors that predict adolescent smoking intention and behaviour $7,10,11$

A few studies on smoking behaviour among adolescents in Malaysia have been carried out in the past few decades. Most of the studies were focused on identifying prevalence and (intra and interpersonal) factors associated with smoking practices, 2,12,13 in order to reduce incidence of smoking practices among teenagers, which will ultimately reduce the health problems related to smoking among the Malaysian population. However, these studies did not use the human behaviour theory to study smoking behaviour or future behaviour intention. The aims of this study are to utilise a the theory of reasoned action to identify the relationship between attitude and subjective norms with intention to smoke among non-smoking, secondary school-going adolescents 
in selected secondary schools in Peninsular Malaysia.

\section{METHODS}

\section{Study design and sampling}

We derived data from a study investigating the health risk behaviour among upper secondary schools students in selected secondary schools in Peninsular Malaysia which was carried out from May to September 2013 (Malaysian Adolescent Health Risk Behaviour Study (MyAHRB)). The sample was selected via two-stage, stratified, proportionate-to-size sampling. The first strata constisted of secondary schools by Clinical Training Centre (CTC) for public health paramedic. followed by stratification of schools by locality (urban/rural). Two secondary schools were then randomly selected from each district via simple random sampling, followed by stratification of schools by locality (urban/rural). Two secondary schools were then randomly selected from each district via simple random sampling method. The sample size was calculated based on estimated 3\% prevalence of suicide ideation (Suicide ideation was used because the study had several outcomes and calculation of sample size found that prevalence of suicide ideation gave the largest sample size, therefore it was used to ensure sufficient power), maximum tolerable error of $1.5 \%$, design effect of 3 , and non-response rate of $20 \%$.

\section{Data collection}

The validated questionnaire adopted from adapted from the Global School-based student Health Survey (GSHS) ${ }^{14}$ and the Youth Risk Behaviour Surveillance (YRBS) ${ }^{15}$ was used in the study. The data was obtained through selfadministered approach. Prior to data collection, the research team members explained the objectives and items in the questionnaire in detail. Those who obtained consent from their parents and agreed to participate were asked to sign a consent form with assurances of anonymity. No school staff or teachers were present at the venue at the time the questionnaires were administered. Only non-smokers (respondents who answered that they did not smoke in the last 30 days) were included in the study. The dependent variable (intention to smoke) was measured by an item," Do you intend to smoke in the future" with a 7-point Likert-type scale response (higher scores indicate higher intention to initiate smoking). Attitude towards smoking was measured by five 4-point Likert-type scale items (eg. Item- Smoking makes the teeth yellowish; Response- Strongly agree, Agree, Disagree, Strongly disagree). The average score of all five items were, in which higher scores indicated more positive attitude towards smoking. Subjective norm was measured by a 5point Likert scale, from 1 (strongly disagree) to 5 (strongly agree): (I) 'My best friend(s) do not mind my smoking habit”(ii) My parents/guardian(s) do not want me to be involved in smoking behavior", (iii) My family member(s) do not tolerate my smoking behaviour" and (iv) People whom I respect agree that smoking is a bad thing" (reverse), The internal consistency of four items was satisfactory (Cronbach Alpha=0.68). The study protocol, instrument and was approved by the Malaysian Ministry of Education and the Medical Research \& Ethics Committee (MREC), Ministry of Health Malaysia.

\section{Data analysis}

The data were clean prior to analysis. Descriptive statistic was used to describe the characteristic of the respondents, SPSS (Version 22) and AMOS statistical software (Version 22) were used to analyse the relationship between attitude and subjective norms. Parameter estimates were obtained using the Maximum Likelihood Robust (MLR) estimator to account for non-normally distributed data and the small amount of missing data]. The MLR estimator adjusts standard errors using a Huber-White sandwich estimator and scales fit statistics to account for non-normality of observed variables. This estimator accommodates missing completely at random or missing at random data patterns. Two models were analysed, a direct effect model, and a "moderated" model (gender as moderator) using multiple group analysis. No significant difference was observed between the two models, indicating no moderation effect of gender on the overall model. Therefore, the direct effect model was used as the final model. Relative Chi-square $(\mathrm{Cq} / \mathrm{df})$, comparative fit index $(\mathrm{CFI})$, TuckerLewis Index (TLI), and the root-mean-square error of approximation (RMSEA) were used to determine the fit of the SEM, and we considered a fit of less than 5 for relative chi-square, $>0.90$ for the CFI and TLI and $<0.08$ for RMSEA to indicate adequate model fit.

\section{RESULTS}

The response rate was $83.6 \%$ (2991/3577). Among the 3577 students who completed the questionnaire, 373 males and 35 female students are current smokers. A total of 208 respondents did not complete the items on subjective norms, or smoking and attitude toward smoking. Therefore, the analysis was carried out on the remaining 2,376 non smoking students who completed all the items (for independent and dependent variables. The respondents consisted of 963 (40.5\%) males and 1,413 (59.5\%) females. Approximately three fourths of the respondents were Malay $(n=1,812,76.3 \%)$, Chinese $(n=375$, $15.8 \%)$ Indian $(n=181,7.61 \%)$ and others $(n=8$, $0.3 \%)$. The mean age of the respondent is 16.3 years old (Range: 15-17 years) (Table 1) Figure 1 showed almost 22\% (R Square) of the variation in intention to smoke was explained by attitude and subjective norm. The significant relationship between subjective norm ( $r=0.46)$ and attitude with $(r=-0.12)$ with intention to 
smoke was observed. The SEM model was fit with relative chi-square/df ratio of $2.207, \mathrm{CFI}$ of 0.978 , TLI 0.920 and RMSEA score of 0.042 , which indicate adequate fit of the model. No multicollinearity was observed between the latent measurements based on the correlation coefficient of 0.25 between attitude and subjective norms.

Table 1: Social-demographic characteristics of respondents

\begin{tabular}{lcc}
\hline Variables & Number $(\mathbf{n})$ & Percentage (\%) \\
\hline Gender & 963 & 40.5 \\
Male & 1413 & 59.5 \\
Female & & \\
Ethic & 1812 & 76.3 \\
Malay & 375 & 15.8 \\
Chinese & 181 & 7.61 \\
Indian & 8 & 0.3 \\
Others & & \\
& & 94.2 \\
Marital status of parents & 2233 & 5.8 \\
Married & 127 & \\
Divorce & & \\
\end{tabular}

\section{DISCUSSION}

This is the first paper in Malaysia to discuss the relationship between intention to smoke among non-smoking adolescents using the Theory of Reasoned Action (TRA). The study revealed that TRA substantially explained the variation in intention to smoke, the proportion of variation explained in the study was higher reported in a systematic review by Topa and Mariaono 2010 on 35 studies $(12 \%)^{16}$. However, the proportion of variation explained is only half as reported by Lazuras ${ }^{17}$ among youth in Greece of $36 \%$. Inclusion of both smokers and non-smokers in Lazuras study might be a contributing factor for the differences with the current study.

The negative relationship between attitude and intention to smoke in this study indicates that negative attitude toward smoking reduces intention to smoke in future. The finding was inline with findings from studies by Topa and Mariano $2010^{16}$, Lazuras $2014{ }^{17}$, and Pires et al, $2014{ }^{18}$ who reported $18 \%$ of variation in intention to smoke was explained by the attitude variable. Our finding is also congruent with another study ${ }^{19}$ among secondary school students in Kota Tinggi, district, which reported a significant association between attitude and intention to smoke among non smokers (AOR 2.23, 95\% Cl 1.59-3.45). The finding in this study suggests attitude is a predictor that should be given due attention in anti-smoking and health promotion programmes to curb smoking initiation among non-smoking adolescents. A detailed comparison of previous studies is given in Table 2 .
Our results are in-line with previous studies by Alanazi et al., $2017^{20}$, Bashirin et al $2012^{21}$, a systematic review and meta-analysis by Tupa and Adriano 201016 and a longitudinal study by Harakeh et al (2004) 22 which show significant association between subjective norm and intention to smoke. However, contrary findings were reported among youth in a study by Mcmillan et. al. (2005) ${ }^{23}$ among 741 youths in England. We postulate the current findings might be attributed to the nature of the Malaysian population being a patriarchal and collectivist society ${ }^{2}$. Adolescents' perception of their parents/guardian and other important persons precede their own opinion and influence their intention. In addition, adolescence is a period of identity searching and peers are their references in view of similarity of characteristic between them. This might explain the stronger relationship between subjective norm with intention, compared to attitude ${ }^{24}$. As suggested by Guo et. al. ${ }^{25}$, normative influences against tobacco consumption are powerful among Asians.

The study was not without limitation. First, because of the cross-sectional design, causal relationship cannot established between the independent variable and outcome. Second, the finding can only be generalised to secondary school students in selected secondary schools in Peninsular Malaysia. Finally, other factors related to intention to smoke such as effect of tobacco advertisement 10, and parents', household members and peers' smoking status ${ }^{11}$ were not investigated in this study. Even though our models fit the data reasonably well, it is possible that the addition of those variables will improve the model by increasing the proportion of explained variation in intention to smoke. 


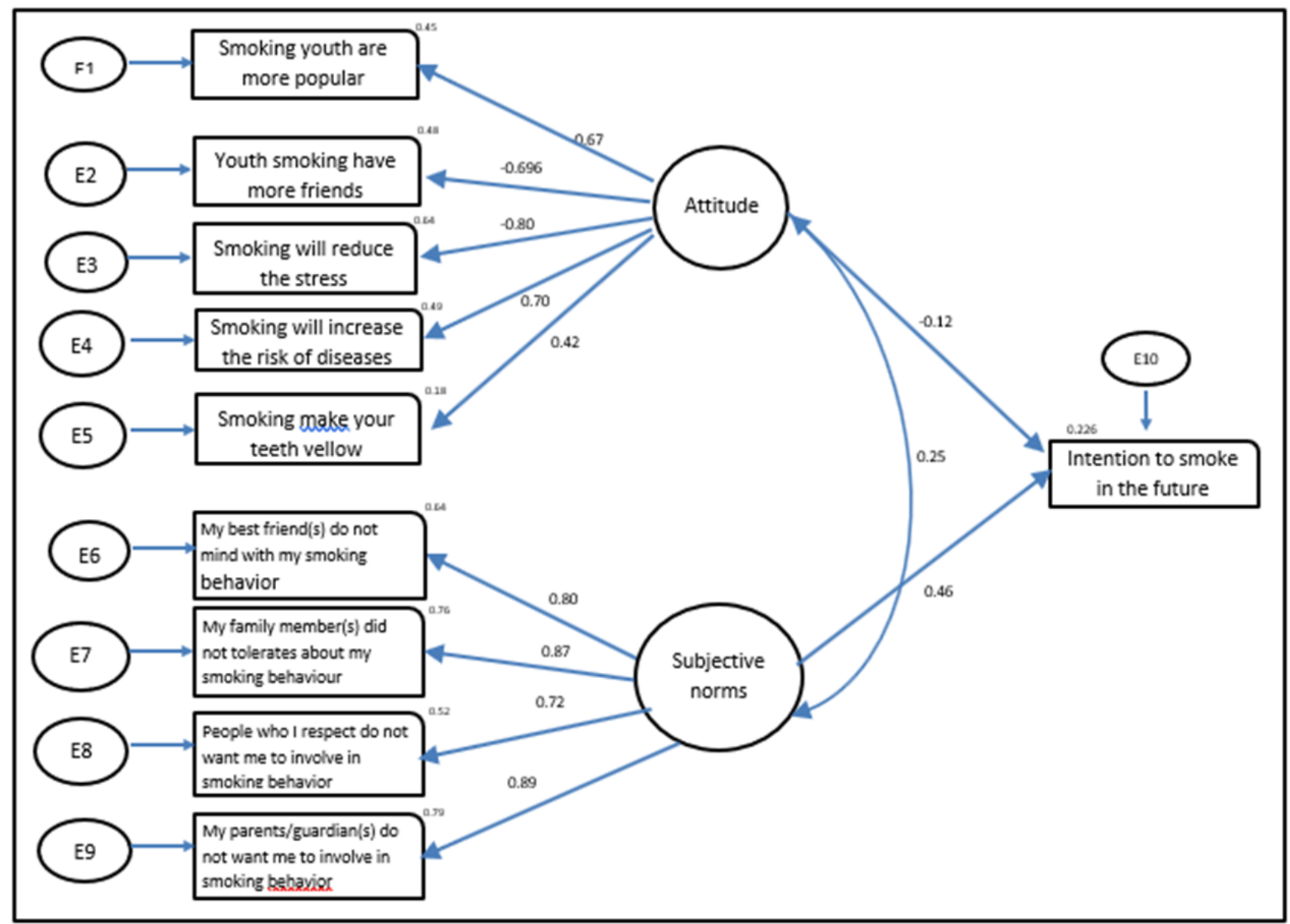

Figure 1. Relationship between attitude, injunctive and descriptive norm using structural equation modelling. (Chi-Square(df)=65.20(25), $p<0.001$; Chi-Square/df $(<=5) f=2.207 ; C F I(>=0.9)=0.978$; $\operatorname{IFI}(>=0.9)=0.988 ; \mathrm{TLI}(>=0.9)=0.920 ; \operatorname{RMSEA}$

Table 2: Comparison of findings of previous studies on relationship between social norm and attitude toward smoking intention among youth

No Author Finding

1 Harakeh al., 2004

2 Topa and, Moriano JA 2010

$3 \quad$ Lazuras 2015

4 Alanazi, N.H., Lee, J.W., Dos Santos, H. et al 2017
The longitudinal study among 1,173 secondary school children found that the positive correlation of attitude and social norm with intention to smoke ( $\mathrm{r}=0.32$ \& 0.19 respectively)

The analysis of 35 data sets $(\mathrm{N}=267,977)$, containing 219 effect sizes between the model variables, a meta-analytic structural equation modeling approach (MASEM).

(1) intentions were positive correlate with intention to smoke (weighted mean $r=0.16$ ),

(2) subjective norms was positive correlated with intention to smoke, (weighted mean $r=0.20$ ).

A cross-section survey-based among 251 Greek secondary school students $(M$ age $=16.1$ years, $61.2 \%$ females $)$ found that social norms overall predicted $36.4 \%$ (Adjusted $R$ Square $\left(R^{2}\right)$ of the variance in intentions.

Four hundred six current waterpipe smokers who initially had started tobacco use with the waterpipe were recruited from 15 waterpipe lounges in 2015. Study found that Cigarette smoking and intention to smoke cigarettes were predicted by attitude and perceived

behavioral control. And subjective norm had a statistically significant indirect effect on intentions through attitude and perceived behavioral control 
Therefore, future studies should include all the factors identified as predictors of smoking intention, to identify the significant contributors to smoking intention among non-school secondary school students in Malaysia. In addition, studies should be carried out in different settings and localities in Malaysia to further cover the breadth of factors that contribute to smoking intention among non-smoking adolescents.

\section{CONCLUSION}

The study revealed that the theory of reasoned action can be used to predict intention to smoke among school-going adolescents. Anti-smoking programmes should incorporate intrapersonal factors in anti-smoking measures to address and reduce smoking initiation among youth in Malaysia.

\section{Conflict of interest}

The authors declare no potential conflict of interest.

\section{Acknowledgements}

We would like to thank the Director-General of Health in Malaysia for his permission to publish this paper.

\section{REFERENCES}

1. Institute of Public Health. National Health \& Morbidity Survey 2015. . Malaysia: Ministry of Health; 2015.

2. Lim KH, Lim HL, Teh CH, Kee CC, Khoo YY,Subash Shander G, Jane Ling MY, Sumarni MG, Tee EO. Smoking among school-going adolescents in selected secondary schools in Peninsular Malaysia- findings from the Malaysian Adolescent Health Risk Behaviour (MyaHRB) study. Tobacco Induced Diseases 2017;15:9

3. Zhang $Q, Y u B$, Chen X, et al. Patterns of smoking initiation during adolescence and young adulthood in South-West China: findings of the National Nutrition and Health Survey (2010- 2012)BMJ Open 2018;8:e019424. doi: 10.1136/ bmjopen-2017-019424

4. Badr HE, Francis K. Psychosocial perspective and suicidal behaviors correlated with adolescent male smoking and illicit drug use, Asian J Psychiatr. 2017;37:51-57.

5. World Health Organization (WHO), 2015. Tobacco. Fact Sheet N 339. Retrieved from. (Accessed 10 February 2020). http: //www. who.int/mediacentre/f actsheets/fs339/en/.

6. Kelder SH, Perry CL, Klepp K-I, Lytle LL Longitudinal tracking of adolescent smoking, physical activity, and food choice behaviors. Am J Public Health,1994; 84: $1121-1126$.

7. Lim KH, Sumarni MGi, Kee CC, Lim KK, Lim HL, Teh $\mathrm{CH}$, Chan YY, Yeo LY, Fiona Goh SC, Khoo YY, Chong ZL, Normala I, Amal NM. Prevalence and Factors Associated with Smoking Intentions among Non-smoking and Smoking Adolescent in Kota Tinggi, Johor, Malaysia. Asian Pac J Cancer Prev. 2014;15(10):4359-66.

8. Zhu C, Cai Y, Ma J, et al. Predictors of intention to smoke among junior high school students in Shanghai, China: an empirical test of the information-motivation-behavioral skills (IMB) model. PLoS One. 2013;8(11):e80482.

9. Fishbein M, Azjen I (1975). Belief, attitude, intention, and behaviour. An Introduction to theory and research. Reading, MA: AddisonWesley.

10. Stroup AM, Branstetter SA, Effect of e-cigarette advertisement exposure on intention to use ecigarettes in adolescents, Addic Behav, 2018;82:1-6.

11. McGee CE, Trigwell J, Fairclough SJ, Murphy RC, Porcellato L, Ussher M\& Foweather $L$ Influence of family and friend smoking on intentions to smoke and smoking-related attitudes and refusal self-efficacy among 9-10 year old children from deprived neighbourhoods: a cross-sectional study. BMC Public Health 2015 15: 225.

12. Nor A, Zulkefli M, Rahmah MA, Lye MS, Md Said S, Fazilah S, Shamsul Azhar S. smoking behavior among adolescents in rural schools in Malacca, Malaysia - a case- control study. Pertanika J Sci \& Technol. 2015;23(1):13-28.

13. Lim KH, Teh CH, Lim HL, Lau KJ, Kee CC, Sumarni MG, Chan YY, Mohd Yusoff S, Hasimah I, Nor Azian MZ, Leni T, Lim KK, Cheong SM, Normala I Muhammad Fadhli MY. Smoking among Secondary School Students in 
Kota Tinggi, Johor, Malaysia -Findings from a Cross-Sectional Study. Asian Pac J Cancer Prev, 2015;16(11):45634570.

14. Centers of Disease Control and Prevention.Global School Health Survey (GSHS). questionnaire. https://www.cdc.gov/gshs/question naire/index.htm(Acessed on 19.2.2021)

15. Centers of Disease control and Prevention. Youth Behavior Risk Surveillance. 2013. https: / /www.cdc.gov/healthyyou.... Accessed on 29 Dec 2015.

16. Topa G, Moriano JA. Theory of planned behavior and smoking: metaanalysis and SEM model. Subst Abuse Rehabil. 2010;1:23-33.

17. Lazuras L. Normative influences on intentions to smoke among Greek adolescents: the moderating role of smoking status. Tob Induc Dis. 2014;12(1):5.

18. Pires PP, Ribas, RC, and Borzekowski, DLG. Attitudes and intentions to smoke: a study of young Brazilian children. Child Care Health Dev,2015; 41: 1124- 1130.

19. Lim KH, Sumarni MG, Kee CC, Lim KK, Lim HL, Chan Y Yi, The CH, Lai WY, Ong SY, Yeo LY, Norhamimah A, Wymen S, Normala I. Correlates of Susceptibility to Smoking among Secondary School Students in Kota Tinggi District, Johor, Malaysia. Asian Pac J Cancer Prev. 2013;14(11):6971-6978.

20. Alanazi, N.H., Lee, J.W., Dos Santos, $\mathrm{H}$. et al. The use of planned behavior theory in predicting cigarette smoking among Waterpipe smokers. Tob. Induced Dis. 2017. 15,29

21. Bashirian $S$, Hidarnia $A$, Allahverdipour $\mathrm{H}$, Hajizadeh $\mathrm{E}$. Application of the theory of planned behavior to predict drug abuse related behaviors among adolescents. J Res Health Sci. 2012;12(1):54-60

22. Harakeh Z, Scholte RHJ, Vermulst AA, de Vries H, Engels RCME. Parental factors and adolescents' smoking behavior: an extension of The theory of planned behavior. Prev Med, 2004;39(5):951-961.

23. McMillan B, Higgins AR, Conner M. Using an extended theory of planned behaviour to understand smoking amongst schoolchildren. Addict Res Theory. 2005;13(3):293- 306.

24. Santrock JW.(2018). Life-Span Development. McGraw-Hill Education, United States. $\mathrm{OH}$

25. Guo Q, Johnson CA, Unger JB, et al. Utility of the theory of reasoned action and theory of planned behavior for predicting Chinese adolescent smoking. Addict Behav. 2007;32:1066-1081. 